\title{
Fatores de Risco e de Proteção na Rede de Atendimento a Crianças e Adolescentes Vítimas de Violência Sexual*
}

\author{
Risk and Protective Factors in the Resource Network for Children \\ and Adolescences Victims of Sexual Violence
}

\author{
Luísa F. Habigzang, Gabriela Azen Azevedo, Sílvia Helena Koller, Paula Xavier Machado \\ Universidade Federal do Rio Grande do Sul, Porto Alegre, Brasil
}

\begin{abstract}
Resumo
A violência sexual contra crianças e adolescentes é um problema de saúde pública, caracterizado por uma dinâmica complexa, que envolve aspectos psicológicos, sociais e legais, exigindo a intervenção coordenada de diferentes instituições. Este estudo apresenta o mapeamento de fatores de risco e de proteção na rede de atendimento a crianças e adolescentes vítimas de violência sexual identificados nos processos jurídicos do Ministério Público do Rio Grande do Sul/Brasil por violência sexual, no período entre 1992 e 1998. A análise de 71 expedientes apresenta as intervenções realizadas pelas instituições que compuseram a rede. Os resultados apontaram a dificuldade dos órgãos de proteção intervirem efetivamente nos casos. Verificou-se a falta de comunicação entre as instituições para articular as medidas de proteção necessárias e acompanhar seu cumprimento. Estes resultados sugerem a necessidade de capacitar a rede de atendimento, visando a compreensão real dos casos, bem como a condução de intervenções adequadas.

Palavras-chave: Abuso sexual infantil; rede de proteção; fatores de risco; fatores de proteção.
\end{abstract}

\begin{abstract}
Sexual violence against children and adolescences is a public health concern, characterized by a complex dynamics, which involves psychological, social and legal aspects, demanding the coordinated intervention of different institutions. This study presents the mapping of risk and protective factors in resource network for children and adolescences victims of sexual violence, who were identified in the 1992-1998 judicial processes of the Ministério Público (District Attorney's Office) of the state of Rio Grande do Sul, Brazil. The analysis of 71 files present the interventions that were performed by the institutions that composed the network. The results pointed out the difficulty of the protection services to intervene in the cases. The lack of communication among the institutions to articulate the necessary protection measures and to follow-up on their implementation was verified. These results suggest the need to qualify the services of the network, seeking the real understanding of the cases, as well as performing appropriate interventions.

Keywords: Child sexual abuse; prevention network; risk factors; protective factors.
\end{abstract}

O abuso sexual contra crianças e adolescentes tem sido considerado um problema de saúde pública em vários países, inclusive no Brasil, devido a alta prevalência na população e aos prejuízos para o desenvolvimento psicológico e social da vítima e de seus familiares (Gonçalves \& Ferreira, 2002; Habigzang \& Caminha, 2004; Osofsky, 1995). Este é definido como todo ato ou jogo sexual, relação hetero ou homossexual, cujo agressor esteja em estágio de desenvolvimento psicossexual mais adiantado que a criança ou adolescente. Tem por finalidade estimulá-la sexualmente ou utilizá-la para obter estimulação sexual. Estas práticas eróticas e sexuais são impostas às crianças ou aos adolescentes pela violência física, ameaças ou indução de sua vontade. Pode variar desde atos em que não existam contatos físicos,

\footnotetext{
"Endereço para correspondência: Rua Ramiro Barcelos, 2600, Sala 104, Porto Alegre, RS, Brasil, 90035-003. http://www.psicologia.ufrgs.br/cep_rua/ luisa.h@terra.com.br

A equipe agradece ao Ministério Público do Estado do Rio Grande do Sul pelo apoio e disponibilização de material para a pesquisa.
}

mas que envolvem o corpo (toques, assédio, voyeurismo, exibicionismo), aos diferentes tipos de atos com contato físico sem penetração (sexo oral, intercurso interfemural) ou com penetração (digital, com objetos, intercurso genital ou anal). Engloba, ainda, a situação de exploração sexual, visando ao lucro, como a prostituição e a pornografia (Azevedo \& Guerra, 1989; Gomes, Junqueira, Silva \& Junger, 2002; Kaplan \& Sadock, 1994/1997).

Um levantamento nacional realizado nos Estados Unidos, entre 2002 e 2003, sobre a vitimização de crianças e adolescentes com idade entre dois e dezessete anos sugeriu, entre seus resultados, que uma a cada doze crianças ou adolescentes ( 82 em cada 1000 participantes) foram vítimas de alguma forma de violência sexual (Finkelhor, Ormrod, Turner \& Hamby, 2005). No Brasil, algumas pesquisas vêm sendo conduzidas para estimar a epidemiologia de abuso sexual contra crianças e adolescentes. Em uma pesquisa desenvolvida na região metropolitana de Porto Alegre foram estudados 1.754 registros de crianças e adolescentes 
de zero a 14 anos que sofreram algum tipo de violência, entre 1997 e 1998. Nesta foram consultadas 75 instituições que prestam atendimento a crianças e adolescentes, tais como conselhos tutelares, casas de passagem, hospitais, órgãos do Ministério Público, entre outros. Com relação aos abusos sexuais, os números apontam que $79,4 \%$ das vítimas são meninas e $20,6 \%$ são meninos. Também foi investigado o local de ocorrência destes abusos e foi constatado que $65,7 \%$ ocorreram na residência da vítima, $22,2 \%$ na rua, $9,8 \%$ na residência de terceiros e 2,4\% em instituições públicas (Kristensen, Oliveira \& Flores, 1999). Outro levantamento, realizado no Ambulatório de Maus Tratos de Caxias do Sul/RS, entre 1998 e 1999, constatou um significativo predomínio de abuso sexual (59\%) e de vítimas do sexo feminino (77\%). A maioria dos abusos ocorreu com crianças entre seis e nove anos de idade (35\%), sendo o pai o responsável pelas agressões em 33\% dos casos (De Lorenzi, Pontalti \& Flech, 2001). Estes dados estão em consonância com a análise realizada em 71 processos jurídicos do Ministério Público do Rio Grande do Sul no período entre 1992 e 1998 por violência sexual (Habigzang, Azevedo, Koller \& Machado, 2005). Esta análise apontou que a maioria das vítimas foi do sexo feminino (80,9\%) e tinha entre cinco e dez anos quando submetidas pela primeira vez à violência sexual. Além disso, o principal contexto onde ocorreu a violência sexual foi a própria casa da vítima $(66,7 \%)$ e o agressor era um membro da família ou alguém de confiança desta.

Entretanto, estes resultados revelam apenas parcialmente o problema, uma vez que a maioria dos casos de abuso sexual envolvendo crianças e adolescentes não é denunciada, devido aos sentimentos de culpa, vergonha e tolerância da vítima. Além disso, outros fatores contribuem para esta condição, tais como: a relutância de alguns médicos em reconhecer e relatar o abuso, a insistência de tribunais por regras estritas de evidência e o medo da dissolução da família com a revelação (Furniss, 1993; Zavaschi, Telelbom, Gazal \& Shansis, 1991).

A experiência de abuso sexual pode afetar o desenvolvimento de crianças e adolescentes de diferentes formas, uma vez que alguns apresentam efeitos mínimos ou nenhum efeito aparente, enquanto outros desenvolvem severos problemas emocionais, sociais e/ou psiquiátricos (Elliott \& Carnes, 2001; Heflin \& Deblinger, 1996/1999; Runyon \& Kenny, 2002; Saywitz, Mannarino, Berliner, \& Cohen, 2000). O impacto do abuso sexual está relacionado a fatores intrínsecos à criança, tais como vulnerabilidade e resiliência (temperamento, resposta ao nível de desenvolvimento neuropsicológico) e a existência de fatores de risco e proteção extrínsecos (recursos sociais, funcionamento familiar, recursos emocionais dos cuidadores e recursos financeiros, incluindo acesso ao tratamento). Algumas conseqüências negativas são exacerbadas em crianças que não dispõem de uma rede de apoio social e afetiva (Brito \& Koller, 1999; Saywitz et al.).

A rede de apoio social é definida como o conjunto de sistemas e de pessoas significativas que compõem os elos de relacionamento existentes e percebidos pela criança. A esse construto foi, recentemente, agregado o elemento afetivo, em função da importância do afeto para a construção e a manutenção do apoio. Dessa forma, a possibilidade de se desenvolver adaptativamente e de dispor de recursos que incrementem os determinantes mencionados, protege a criança de doenças, sintomas psicopatológicos e sentimentos de desamparo, mesmo quando ela está frente a situações adversas. O apoio social e afetivo está relacionado com a percepção que a pessoa tem de seu mundo social, como se orienta nele, suas estratégias e competências para estabelecer vínculos (Brito \& Koller, 1999).

As crianças tornam-se mais vulneráveis frente a situações de risco, tais como abuso sexual, demonstrando suscetibilidade individual, quando não contam com uma rede de apoio social e afetivo que seja eficaz e efetiva na prevenção de doenças e de características desadaptativas. Essa vulnerabilidade potencializa os efeitos negativos de situações estressantes. Por outro lado, a criança que é capaz de superar adversidades é definida como resiliente, ou seja, capaz de buscar alternativas eficazes que a auxiliarão a enfrentar de forma satisfatória os eventos de vida negativos. É importante ressaltar que a resiliência possui bases tanto constitucionais quanto ambientais, sendo o resultado da interação das características individuais com a complexidade do contexto social (Morais \& Koller, 2004; Brito \& Koller, 1999).

Os conceitos de resiliência e vulnerabilidade envolvem fatores de risco e de proteção. Risco está associado às características ou aos eventos que podem levar a resultados ineficazes, enfraquecendo a pessoa diante da situação de estresse. Em contrapartida, fatores de proteção inibem a intensidade deste risco e têm sido identificados, principalmente, no cuidado estável oferecido pela família, que reforça a identificação com modelos e papéis; nas características pessoais, como a habilidade para resolver problemas, a capacidade de cativar pessoas, competência social, crenças de controle pessoal sobre os eventos de vida e senso de auto-eficácia; e, na possibilidade de contar com o apoio social e emocional de grupos externos à família, diante de eventos estressores. É importante salientar que os fatores de risco e proteção não são categorias fixas definidas a priori, mas se constituem como tal dependendo do contexto no qual ocorrem (De Antoni \& Koller, 2001).

Apesar da complexidade e da quantidade de variáveis envolvidas no impacto do abuso sexual na criança, esta experiência é considerada um importante fator de risco para o desenvolvimento de psicopatologias (Saywitz et al., 2000), sendo que crianças ou adolescentes podem desenvolver quadros de depressão, transtornos de ansiedade, alimentares, dissociativos, hiperatividade e déficit de atenção e transtorno do estresse pós-traumático (Cohen, Mannarino, \& Rogal, 2001; Duarte \& Arboleda, 2004; Habigzang \& Caminha, 2004; Heflin \& Deblinger, 1996/1999; Runyon \& Kenny, 2002). Além disso, estas podem apresentar alterações comportamentais, cognitivas e afetivas, tais como sentimentos de culpa, diferença em relação aos pares, desconfiança, conduta hipersexualizada, baixo rendimento escolar, 
abuso de substâncias, ideações ou tentativas de suicídio, fugas do lar, isolamento social, irritabilidade (Amazarray \& Koller, 1998; Cohen \& Mannarino, 2000; Cohen et al.; Habigzang \& Caminha, 2004; Jonzon \& Lindblad, 2004).

Considerando os dados epidemiológicos e o impacto negativo que o abuso sexual pode desencadear, bem como as dimensões sociais, jurídicas e psicológicas que envolvem este complexo fenômeno, qualquer intervenção depende da ação coordenada de diferentes profissionais e instituições para que seja efetiva (Amazarray \& Koller, 1998; Gomes, Junqueira, Silva \& Junger, 2002; Gonçalves \& Ferreira, 2002; Habigzang \& Caminha, 2004). Os órgãos de proteção à criança e ao adolescente, tais como os Conselhos de Direito, Conselhos Tutelares, Promotoria e Juizado da Infância e Adolescência, e demais instituições como escolas, postos de saúde, hospitais, abrigos, entre outras, compõem a rede de apoio social para as vítimas e suas famílias. A ação desta rede inicia, na maioria dos casos, com o acolhimento da denúncia de abuso sexual e por esta razão a revelação da criança é um momento crucial que pode, por si só, apresentar um risco de revitimização quando os profissionais não adotam as medidas de proteção previstas em lei.

Neste sentido, o Estatuto da Criança e do Adolescente configurou um resgate da cidadania, através da doutrina da proteção integral. Essa lei tornou obrigatória a notificação de casos suspeitos ou confirmados de maus-tratos contra a criança ou adolescente (Ferreira \& Schramm, 2000). A notificação é um instrumento duplamente importante no combate à violência: ela produz benefícios para os casos singulares e é instrumento de controle epidemiológico da violência. Apesar das determinações legais, a subnotificação da violência é uma realidade no Brasil e a identificação da violência sexual é ainda carregada de muitas incertezas. Além disso, esta questão não tem sido tratada na maioria dos currículos de graduação, logo, muitos profissionais não dispõem de informações básicas que permitam diagnosticá-la (Gonçalves \& Ferreira, 2002). O despreparo da rede é ainda constatado, envolvendo desde os profissionais da área de saúde, educadores e juristas até as instituições escolares, hospitalares e jurídicas, em manejar e tratar adequadamente os casos surgidos. O trabalho nesse campo ainda é fragmentado, desorganizado e em geral metodologicamente difuso (Amazarray \& Koller, 1998).

A intervenção legal, desconhecendo os aspectos psicológicos do abuso sexual e as necessidades terapêuticas da criança e das famílias disfuncionais, produz um dano psicológico adicional à vítima. Por outro lado, os profissionais da saúde mental, negligenciando os aspectos legais do abuso (proteção à criança e prevenção adicional do crime), também podem contribuir para um aumento do dano psicológico sofrido pela criança. Ainda, se os profissionais da saúde não denunciarem a ocorrência do crime ou desconsiderarem sua possível existência, estarão perpetuando o abuso sexual, colaborando com a síndrome de segredo do mesmo e levando adiante uma terapia que não tem valor nenhum para minimizar o impacto físico e psicológico do abuso sexual na criança (Amazarray \& Koller, 1998). Dessa forma, é importante que as ações profissionais não se restrinjam aos campos disciplinares, sendo preciso que tais ações tenham visibilidade no espaço público para que consigam, não só se conectar com a realidade, como também nela intervir (Ferreira \& Schramm, 2000).

Os profissionais e instituições que constituem a rede de apoio social para crianças e famílias vítimas de violência sexual encontram-se diante do desafio de evitar as formas traumáticas de intervenção sem resvalar, contudo, na negligência com que o tema da violência contra crianças tem sido tratado no Brasil, com raras e honrosas exceções (Ferreira \& Schramm, 2000). O presente artigo tem como objetivo apresentar os resultados mais significativos sobre a atuação da rede de atendimento, a partir da análise realizada nos processos jurídicos por violência sexual iniciados e concluídos pelo Ministério Público Estadual do Rio Grande do Sul, no período entre 1992 e 1998. A análise descreve as intervenções dos principais órgãos de proteção a criança e ao adolescente que compuseram a rede de apoio aos casos de violência sexual, bem como apresenta um mapeamento dos principais fatores de risco e de proteção identificados para propiciar subsídios que possibilitem a qualificação da rede.

\section{Método}

Foi realizada uma análise de documentos a partir de todos os processos de casos denunciados de violência sexual ajuizados pelas Promotorias Especializadas na Infância e na Juventude de Porto Alegre - Ministério Público Estadual do Rio Grande do Sul - entre 1992 e 1998, num total de 71 expedientes e 94 vítimas, uma vez que algumas vítimas constavam no mesmo expediente por pertencerem à mesma família.

\section{Material}

Foi utilizada uma ficha de dados ${ }^{1}$, elaborada pela equipe de pesquisa, para coletar informações relacionadas à vítima, à violência sexual, ao agressor, à família e às instituições que constituem a rede de encaminhamentos em cada caso (por ex., Conselho Tutelar, Ministério Público e Juizado da Infância e Juventude), bem como outras instituições (delegacias, hospitais, profissionais, etc.).

\section{Procedimentos}

Cada processo dos casos de violência sexual ajuizado no período foi analisado por uma pesquisadora capacitada do Centro de Estudos Psicológicos sobre Meninos e Meninas de Rua (CEP-RUA), que preencheu a ficha de dados relativa, uma vez que foi necessário interpretar as informações contidas nos expedientes. As fichas de dados foram conferidas uma a uma por outra pesquisadora e, em casos de dúvidas, o instrumento foi analisado por uma terceira pesquisadora, até a obtenção de consenso por discussão. Não houve problemas de consenso nos casos que apareceram discrepâncias iniciais.

\footnotetext{
1 Esta ficha está disponível com a equipe de pesquisa.
} 


\section{Resultados}

O mapeamento das intervenções realizadas pelo Conselho Tutelar, Ministério Público, Juizado da Infância e Adolescência e outras instituições que compõem a rede de atendimento a vítimas de violência sexual, bem como os fatores que facilitaram e dificultaram a efetividade de tais intervenções estão apresentados a seguir:

\section{Conselho Tutelar}

O Conselho Tutelar foi o principal órgão procurado no momento da denúncia da violência. Em todos os casos analisados houve encaminhamento ao Ministério Público, que formalizava as denúncias. Nos 71 processos havia informações sobre outros encaminhamentos adotados pelo Conselho Tutelar. Dentre estes se destacam abrigagem $(98,6 \%)$, tratamento psicológico $(32,4 \%)$, colocação em outra família (31,1\%), departamento de polícia $(25,7 \%)$, instituto médico legal $(9,5 \%)$, termo de responsabilidade/guarda a outros parentes $(9,5 \%)$ e hospital $(6,9 \%)$.

A permanência do caso no Conselho Tutelar foi variada, sendo $8,1 \%$ dos casos duraram menos de uma semana, 1,6\% menos de um mês, 35,4\% tiveram duração de um a nove meses e a maioria deles $(54,8 \%)$, teve duração entre um e seis anos. Outra constatação interessante foi que, juntamente com a denúncia de violência sexual, em dez casos, surgiram outras queixas, como o uso de drogas (dois casos) ou álcool (dois casos) por parte dos perpetradores. Também foram citadas nos processos queixas de fugas das vítimas do lar (dois casos), negligência (dois casos), falta de vagas na rede de ensino regular (um caso) e recusas ao trabalho (dois casos).

Os fatores que contribuíram para a efetividade das intervenções do Conselho Tutelar foram mapeados. Destacaramse o envolvimento de familiares na denúncia e no cumprimento dos encaminhamentos (19\%), o acompanhamento efetivo dos casos (19\%), a aceitação da guarda das vítimas por parte de outros parentes ou família substituta $(15,5 \%)$, o pedido de prisão do agressor (13,8\%) e a rapidez na condução do caso (12,1\%). Alguns fatores prejudicaram a atuação do Conselho Tutelar nos casos. O principal deles foi o fato de os familiares não cumprirem os encaminhamentos e não responderem aos chamados para comparecimento às audiências no Conselho (30,9\%). Também foram identificadas falta de investigação da violência sexual (16,2\%), falta de condições psicológicas e financeiras dos pais para permanecerem com os filhos $(11,8 \%)$ e ausência de laudo médico $(8,8 \%)$.

\section{Ministério Público}

O motivo de encaminhamento do caso ao Ministério Público, em 87 dos 94 casos, foi a violência sexual. Outros motivos de encaminhamento identificados nos processos foram: situações de negligência $(24,5 \%)$, abuso físico e psicológico $(17,1 \%)$, abandono (4,3\%), tentativa ou suspeita de violência $(6,4 \%)$, exploração sexual comercial $(2,1 \%)$ associadas à questão do abuso sexual. Os principais reque- rentes do expediente no Ministério Público foram: o Conselho Tutelar em 47,9\% dos casos, a mãe em 10,6\%, a Fundação Estadual do Bem-Estar do Menor em 9,6\% e o Juizado em 9,6\%. O Ministério Público, enquanto acompanhou os casos, fez encaminhamentos para diversas instituições, como locais de atendimento a vítimas, hospitais, Vara Criminal, Conselho Tutelar, abrigos e Juizado da Infância e Juventude. O tempo de permanência dos casos, no Ministério, na maioria das vezes (65,9\%), ultrapassou um ano. Em 35,3\% deles, o tempo de duração do processo foi de cinco anos para mais. A efetivação dos encaminhamentos foi informada em 55 expedientes. Destes, $52,7 \%$ dos encaminhamentos não foram efetivados, $40 \%$ foram efetivados no período entre uma semana e um mês e o restante foi efetivado em até sete dias. Estes dados revelam que mais da metade dos encaminhamentos do Ministério Público não foram cumpridos e que a maioria dos encaminhamentos cumpridos demoraram em ocorrer, expondo a vítima a uma situação de vulnerabilidade.

As medidas judiciais promovidas pelo Ministério Público estavam informadas em 89 dos 94 casos. Estas consistiram em destituição do pátrio poder de ambos genitores (19,1\%), do genitor $(34,8 \%)$ e da genitora $(15,7 \%)$; assim como suspensão do pátrio poder de ambos genitores (3,4\%), do genitor $(3,4 \%)$ e da genitora $(1,1 \%)$. Outras medidas ainda adotadas foram remoção de tutor $(23,6 \%)$, afastamento do agressor do lar $(1,1 \%)$, abrigagem ou manutenção da vítima em abrigo $(10,1 \%)$. Além das medidas, diversas liminares, de caráter emergencial, foram despachadas antes da decisão final. As principais foram: ação de afastamento do agressor do lar (49,3\%), ação solicitando proibição de visitas à vítima ou visita monitorada (16,4\%), ação de suspensão do pátrio-poder de ambos os genitores (13,4\%), ação de suspensão do pátrio-poder do genitor (13,4\%), ação de guarda e tutela (11,9\%) e ação de suspensão do pátrio-poder da genitora $(10,4 \%)$.

Diversos fatores contribuíram para uma melhor atuação do Ministério durante o acompanhamento dos casos. Destacou-se o efetivo acompanhamento do caso por parte do Conselho Tutelar (35,4\% dos casos), apoio familiar (17,7\%), informações sobre o caso nas varas criminais ou polícia $(16,5 \%)$, exames e laudos médicos $(13,9 \%)$ e a rápida atuação do próprio Ministério (12,7\%), entre outros. Também foram constatados fatores que prejudicaram o trabalho do Ministério Público. Os principais foram informações confusas ou ausentes (18,2\%), falta de relatórios do Conselho Tutelar (17\%), dificuldades em relação aos exames médicos (14,8\%), lenta atuação do Conselho Tutelar (13,63\%), agressor continuava a ter contato com as vítimas (13,6\%), falta de representação do caso pelo Conselho Tutelar (12,5\%), ausência de registros das varas criminais $(12,5 \%)$, atuação não protetiva do Conselho Tutelar (10,2\%) e dificuldades em localizar as famílias das vítimas (10,2\%).

\section{Juizado da Infância e da Juventude}

O Juizado da Infância e da Juventude teve como principal função julgar as liminares e medidas judiciais promovidas 
pelo Ministério Público. Em 67,6\% dos casos, as liminares foram deferidas ou parcialmente deferidas. Já no julgamento no juízo de primeiro grau, as medidas foram julgadas como procedentes ou parcialmente procedentes em $78,8 \%$ dos casos. A duração do caso no Juizado ultrapassou um ano em $74,1 \%$ dos casos. Em apenas 32 expedientes havia informação sobre os encaminhamentos realizados pelo Juizado da Infância e da Juventude. Os principais foram à Fundação Estadual do Bem-Estar do Menor (28,1\%), ao Conselho Tutelar para acompanhamento, abrigagem e investigação (25\%), ao Ministério Público (34,4\%), à equipe interprofissional do Juizado (12,5\%), à equipe de manutenção do vínculo para acompanhamento $(9,4 \%)$, à vara criminal solicitando prisão preventiva do agressor $(9,4 \%)$ e a um serviço multidisciplinar para atendimento psicológico da vítima (6,3\%).

Ao longo da investigação dos casos, o Juizado emitiu medidas que visavam à proteção das vítimas. A principal delas foi o mandado de afastamento do agressor do lar $(32,1 \%)$, embora, muitas vezes, ela não tenha sido cumprida. Em $17,9 \%$ dos casos, as vítimas foram internadas para atendimento psiquiátrico ou psicológico. Foram emitidos mandados de busca e apreensão a vítimas em 17,9\% dos casos. Medidas relativas a possíveis guardiões das vítimas, tanto com pedidos para tutela, adoção ou consentimento de guarda estavam presentes em $28,6 \%$ das vezes.

Assim como nas demais instituições, foram investigados os fatores que auxiliaram e que prejudicaram a atuação do Juizado da Infância e da Juventude. Entre os fatores que auxiliaram o trabalho, destacaram-se acompanhamento, comunicação e informações do caso por parte das demais instituições envolvidas $(41,5 \%)$, depoimentos (17\%), encaminhamentos das vítimas, das famílias e/ou agressores para avaliação psicológica $(12,2 \%)$ e os estudos sociais do caso, os laudos psicossociais, avaliações psicológicas ou econômicas $(9,8 \%)$.

O principal fator que prejudicou o trabalho do Juizado foi a ineficiência das outras instituições envolvidas, em $52,2 \%$ dos casos. Outros foram: violência ter sido negada por vítimas, agressores ou mães e depoimentos contra a vítima (em 25,6\% das vezes), ausência de depoimentos de testemunhas, familiares, agressores $(15,6 \%)$, falta de informações de outras instituições $(14,4 \%$ ), o fato de a família não cumprir com os encaminhamentos $(11,1 \%)$, ineficiência do próprio Juizado (10\%) e pais sem condições financeiras e psicológicas para assumirem a guarda dos filhos (10\%).

\section{Outras Instituições}

Outras instituições foram citadas nos expedientes, constituindo a rede de atendimento aos casos. Estas foram abrigos $(91,5 \%)$, polícias civil e militar (72,3\%), hospitais e serviços de saúde em geral ( $57,4 \%)$, serviços de atendimento jurídico $(54,3 \%)$, serviços de atendimento psicológico e psiquiátrico $(48,9 \%)$, serviço de perícia $(34 \%)$, escolas (25,5\%), outras promotorias do Ministério Público (21,3\%), outros Juizados ( $8,5 \%)$, órgãos ou instituições de assistência social (4,3\%), outras comarcas do Juizado da Infância e da Juventude $(2,1 \%)$ e outras $(4,3 \%)$.
Os atendimentos destas instituições envolveram o abrigamento da vítima, investigação policial, defesa do agressor, atendimento e avaliação psicológica, exames e laudos médicos, perícia médica, atendimento médico, assistência social, atendimento psicológico familiar, julgamento das ações penais, entre outros. Nos 71 documentos analisados havia informações sobre os encaminhamentos realizados por estas instituições. Os principais encaminhamentos foram ao Conselho Tutelar (75,3\%), ao Juizado da Infância e Juventude $(75,3 \%)$, ao Ministério Público (37\%), ao atendimento psicológico e psiquiátrico (20,5\%), perícia médica (20,5\%), delegacia de polícia $(15,1 \%)$ e abrigos $(12,3 \%)$.

O tempo de permanência dos casos nestas instituições foi mapeado e foram encontradas informações sobre este aspecto em 66 documentos. A maioria dos casos permaneceu na instituição apenas um dia $(42,4 \%)$ ou no período de uma semana a um mês (34,8\%). Alguns fatores foram apontados como facilitadores da atuação das instituições. Estes fatores foram acompanhamento efetivo do caso pelas instituições, boa adaptação da vítima aos abrigos, confirmação da violência sexual pela vítima e/ou familiares, rápida atuação das instituições, aceitação das medidas aplicadas e intervenções propostas pelas instituições, atuação conjunta das instituições e trocas de informações (laudos e relatórios) entre as instituições.

Por outro lado, foram identificados fatores que prejudicaram a atuação destas instituições. Estes fatores foram o não cumprimento dos encaminhamentos pelos pais e/ou família, evasão da vítima dos abrigos e fuga do lar, dependência de outras instituições para realizar alguns encaminhamentos, falta de informações/relatórios dos atendimentos/laudo/inquérito policial da delegacia de polícia, não julgamento da liminar pelo Juiz da Infância e Juventude, deixando a vítima em situação indefinida na casa de passagem, inexistência de sinais de violência sexual nos exames ginecológicos e do Instituto Médico Legal, falta de acompanhamento do Conselho Tutelar, falta de condições financeiras e psicológicas dos genitores para permanecer com a guarda da vítima, falta de comunicação entre as instituições e relatórios confusos.

\section{Discussão}

Os resultados apontam a existência de diversas instituições na composição da rede de proteção e apoio social às vítimas de violência sexual e suas famílias. Dentre estas instituições, o Conselho Tutelar apareceu como órgão mais procurado para denúncia e acompanhamento dos casos. Isto revela a importância que esta instituição ocupa na rede e na comunidade, apesar das dificuldades que enfrenta para desempenhar suas funções. Por outro lado, a análise dos expedientes possibilitou evidenciar que a falta de acompanhamento dos casos pelo Conselho Tutelar foi um dos fatores que prejudicaram as intervenções do Ministério Público, Juizado da Infância e Juventude e outras instituições. Considerando o conhecimento público do Conselho Tutelar como órgão de proteção e as dificuldades que este encontra, é fundamental que esta instituição receba atenção e que os 
conselheiros tutelares sejam constantemente capacitados para desenvolver com eficácia as medidas de proteção previstas no Estatuto da Criança e do Adolescente em casos de violência sexual.

Outro aspecto interessante levantado pela análise dos expedientes é o tempo de duração dos casos nas diferentes instituições. Os resultados apontaram que a maioria destes permaneceu por mais de um ano na rede de atendimento. Isto aponta a complexidade da intervenção em casos de violência sexual e o comprometimento contínuo que profissionais e instituições estabelecem com as vítimas e suas famílias. Por outro lado, tal fato pode demonstrar também a morosidade das instituições envolvidas, uma vez que, em diversos casos, houve tempo excessivo entre uma intervenção e outra dirigida às vítimas e famílias.

A complexidade da dinâmica da violência sexual é também constatada pela co-morbidade com outras formas de violência. Os resultados apontaram que a denúncia de violência sexual foi acompanhada, na maioria dos casos, da denúncia de outras violações dos direitos da criança e do adolescente. Estes resultados corroboram a literatura especializada que sugere que a violência sexual é para muitas famílias, apenas mais uma forma de violência experienciada (Habigzang \& Caminha, 2004; Kellogg \& Menard, 2003; Thomas, Eckenrode, \& Garbarino, 1997). Outras formas de violência parental e conjugal, tais como abuso físico, abuso psicológico e negligência, bem como a violência comunitária e institucional estão comumente presentes na história de crianças e adolescentes vítimas de violência sexual (Habigzang et al., 2005; De Antoni \& Koller, 2002).

Com relação às intervenções da rede, os resultados revelam que o afastamento da vítima do agressor foi a principal medida de proteção adotada pelas instituições. Também verificou-se a preocupação em oferecer acompanhamento psicológico às crianças e aos adolescentes, embora poucos casos tenham sido efetivamente encaminhados para tal tratamento. A proteção da vítima é fundamental para evitar outras possíveis agressões. Contudo, estes dados apontam que na maioria dos casos, a vítima foi retirada de casa e afastada do convívio de outros familiares, enquanto que o agressor permaneceu em casa. $\mathrm{O}$ afastamento da vítima pode ser compreendido por esta como um castigo, reforçando a crença das crianças de que foram responsáveis pelo abuso (De Antoni \& Koller, 2000; Habigzang \& Caminha, 2004). Dessa forma, o afastamento do agressor e encaminhamento deste, da criança e de cuidadores não-abusivos para acompanhamento psicológico, reduziria o impacto negativo que a violência sexual tem para a vítima e possibilitaria à família reestruturar a experiência abusiva e construir estratégias de proteção e apoio social e afetivo eficazes para as crianças e adolescentes.

Diversas consequiências para as famílias foram constatadas após as intervenções da rede de apoio. Houve tentativas de organização em $35,5 \%$ delas. Em outras, os irmãos foram separados $(35,5 \%)$ ou os pais divorciaram-se (28,9\%). Para $27,6 \%$, os filhos continuaram morando com as mães. Com relação às vítimas, foram constatadas fugas dos abrigos ( $13,6 \%)$ ou de casa (6,2\%). Cinco vítimas (6,2\%) estavam em situação de rua, abandono ou negligência. Quatro delas (5\%) envolveram-se em furtos, exploração sexual comercial e outras infrações. Em relação ao agressor, muitos dos encaminhamentos não foram cumpridos. Apesar de quase a metade deles ter sido afastado do lar, esta foi uma medida que não aconteceu na prática. Novas ocorrências de violência sexual surgiram em $21,1 \%$ das famílias, mesmo após a denúncia e os encaminhamentos acontecerem. Algumas delas (14,5\%) demonstraram desinteresse em ficar com as vítimas. Além disso, 71 famílias não cumpriram com as solicitações das instituições. Foi também constatado que em $2,4 \%$ dos casos a violência sexual passou a ser negada pela vítima. Também foi constatado que a comunicação entre as diversas instituições que atuaram nos casos foi mínima, dificultando que um trabalho em rede e integrado realmente pudesse acontecer. A falta de informações esteve presente em 33,3\% dos casos. Já em $23,3 \%$, as condições de vida da vítima após a intervenção da rede não foram avaliadas pelas instituições. Em $21,7 \%$ dos processos, nenhuma medida foi tomada, enquanto que, em 16,7\% deles, a violência sexual, embora aparecesse, não foi sequer investigada. Dez casos (16,7\%) foram arquivados e $10 \%$ não foram concluídos. Apenas 11,7\% dos casos foram efetivamente acompanhados, e, nestes, tal acompanhamento foi um importante fator de proteção para as vítimas e suas famílias.

A análise dos documentos possibilitou o mapeamento de fatores de risco e de proteção para a criança ou adolescente vítima do abuso sexual e sua família. Entre os fatores de proteção identificados destacam-se: a saída da vítima do contexto abusivo, a revelação da violência sexual, o bom vínculo entre os familiares (família nuclear e/ou extensa), o bom vínculo entre a mãe e os filhos e a rede de apoio social. Os fatores de risco encontrados foram: a falta de fiscalização quanto à medida de afastamento do agressor, a falta de efetividade da rede de apoio, a negação da violência sexual pela família, o abuso de álcool e drogas, a dependência financeira do agressor e outras formas de violência (abuso físico, psicológico e negligência) associadas ao abuso sexual no contex to familiar e comunitário.

\section{Considerações Finais}

As informações coletadas a partir da análise dos processos jurídicos disponíveis no Ministério Público Estadual sobre os casos de violência sexual contra crianças e adolescentes permitiram compreender como estão sendo descritos os casos, bem como identificar os fatores de proteção e de risco envolvidos no contex to familiar e na rede de proteção. No entanto, a falta de informações em muitos expedientes analisados foi um aspecto que prejudicou o mapeamento e o trabalho da equipe de pesquisa.

A violência sexual contra crianças e adolescentes é um fenômeno complexo, envolvendo questões jurídicas, psicológicas, sociais para compreender as múltiplas facetas do problema. Dessa forma, o trabalho interdisciplinar é fundamental. Quando a intervenção legal desconhece os aspec- 
tos psicológicos da violência sexual e as necessidades terapêuticas da criança e das famílias disfuncionais, pode produzir um dano psicológico adicional à vítima. Por outro lado, os profissionais da saúde mental, negligenciando os aspectos legais da violência (proteção à criança e prevenção adicional do crime), também contribuem para um aumento do dano psicológico sofrido pela vítima (Amazarray \& Koller, 1998). A efetividade da intervenção e do tratamento desses casos depende, em grande parte, da boa coordenação e comunicação entre os profissionais e serviços envolvidos (Zavaschi et al., 1991).

O envolvimento das famílias das vítimas de abuso sexual, nas intervenções judiciais, é tão importante quanto um trabalho interdisciplinar efetivo. Foi possível constatar que, nos casos em que as famílias não estavam envolvidas, os encaminhamentos das instituições não foram cumpridos, uma vez que, sendo as vítimas crianças e adolescentes, dependiam dos familiares para serem conduzidas aos serviços especializados. Este fato foi um fator de risco para as vítimas, que não receberam um acompanhamento adequado, $\mathrm{e}$ prejudicou o trabalho dos profissionais participantes da rede de apoio. Seria recomendável que as intervenções terapêuticas adotassem uma abordagem familiar em seu trabalho.

Os resultados deste estudo apontam para a dificuldade dos órgãos de proteção à criança e ao adolescente intervirem efetivamente nos casos avaliados. Verificou-se a falta de comunicação entre os serviços que compõem a rede para articular as medidas de proteção necessárias e acompanhar seu cumprimento. Algumas informações apareciam de forma repetida e superficial, inclusive em laudos técnicos profissionais, como se apenas o processo houvesse sido analisado e não a vítima e a família envolvidas. E em uma avaliação mais crítica, alguns processos se tomados de trás para frente, davam a impressão que a real causa do encaminhamento havia sido esquecido na trajetória dos casos. Ou seja, se o processo fosse folheado das páginas finais para as iniciais não seria possível, em muitos deles, identificar qual era exatamente a causa da denúncia, antes de se chegar às primeiras páginas. Este fato, aliado às repetições e cópias de laudos, falta ou imprecisão de informações revela a necessidade de capacitar com maior competência a rede que está fazendo este atendimento. Constata-se a necessidade emergente de criar serviços especializados e capacitar os profissionais que trabalham com essas crianças e com suas famílias, permitindo-lhes obter uma compreensão real dos casos, bem como conduzir uma intervenção adequada.

\section{Referências}

Amazarray, M. R., \& Koller, S. H. (1998). Alguns aspectos observados no desenvolvimento de crianças vítimas de abuso sexual. Psicologia Reflexão e Crítica, 11 (3), 546-555.

Azevedo, M. A., \& Guerra, V. N. A. (1989). Crianças vitimizadas: A síndrome do pequeno poder. São Paulo, SP: IGLU.

Brito, R. C., \& Koller, S. H. (1999). Redes de apoio social e afetivo e desenvolvimento. In A. M. Carvalho (Ed.). O mundo social da criança: Natureza e cultura em ação (pp. 115-130). São Paulo, SP: Casa do Psicólogo.
Cohen, J. A., \& Mannarino, A. P. (2000). Predictors of treatment outcome in sexually abused children. Child Abuse $\mathbb{S}^{\circ}$ Neglect, 24(7), 983-994.

Cohen, J. A, Mannarino, A. P., \& Rogal, S. (2001). Treatment practices for childhood posttraumatic stress disorder. Child Abuse \& Neglect, 25, 123-135.

De Antoni, C., \& Koller, S. H. (2000). A visão sobre família entre as adolescentes que sofreram violência intrafamiliar. Estudos de Psicologia, 5, 347-381.

De Antoni, C., \& Koller, S. H. (2001). O psicólogo ecológico no contexto institucional: Uma experiência com meninas vítimas de violência. Revista Psicologia: Ciência e Profissão, 21(1), 14-29.

De Antoni, C., \& Koller, S. H. (2002). Violencia doméstica e comunitária. In M. L. J. Contini, S. H. Koller \& M. N. S. Barros (Eds.), Adolescência e Psicologia: Concepções, práticas e reflexões críticas (pp. 85-91). Brasília, DF: Conselho Federal de Psicologia.

De Lorenzi, D. R. S., Pontalti, L., \& Flech, R. M. (2001). Maus tratos na infância e adolescência: Análise de 100 casos. Revista Científica da AMECS, $10(1), 47-52$.

Duarte, J. C., \& Arboleda, M. R. C. (2004). Sintomatologia, avaliação e tratamento do abuso sexual infantil. In V. Caballo (Ed.), Manual de Psicologia Clínica infantil e do adolescente: Transtornos gerais (pp. 293-321). São Paulo, SP: Santos.

Elliott, A. N., \& Carnes, C. N. (2001). Reactions of nonoffending parents to the sexual abuse of their child: A review of the literature. Child Maltreatment, 6(4), 314-331.

Ferreira, A. L., \& Schramm. F. R. (2000). Implicações éticas da violência doméstica contra criança para profissionais de saúde. Revista de Saúde Pública, 34(6), 659-665.

Finkelhor, D., Ormrod, R., Turner, H., \& Hamby, S. L. (2005). The victimization of children and Youth: A comprehensive, national survey. Child Maltreatment, $10(1), 5-25$

Furniss, T. (1993). Abuso sexual da criança: Uma abordagem multidisciplinar. Porto Alegre, RS: Artes Médicas.

Gomes, R., Junqueira, M. F. P, Silva, C. O., \& Junger, W. L (2002). A abordagem dos maus-tratos contra a criança e o adolescente em uma unidade pública de saúde. Ciência E̊ Saúde Coletiva, $7(2), 275-283$.

Gonçalves, H. S., \& Ferreira, A. L. (2002). A notificação da violência intrafamiliar contra crianças e adolescentes por profissionais da saúde. Caderno de Saúde Pública, Rio de Janeiro, 18(1), 315-319.

Habigzang, L. F., \& Caminha, R.M. (2004). Abuso sexual contra crianças e adolescentes: Conceituação e intervenção clínica. São Paulo, SP: Casa do Psicólogo.

Habigzang, L. F., Azevedo, G. A., Koller, S. H., \& Machado, P. X. (2005). Abuso sexual infantil e dinâmica familiar: Aspectos observados em processos jurídicos. Psicologia teoria e Pesquisa. 21(03), 341-348.

Heflin, A. H., \& Deblinger, E. (1999). Tratamento de um adolescente sobrevivente de abuso sexual na infância. In M. Reinecke, F. Dattilio \& A. Freeman (Eds.), Terapia cognitiva com crianças e adolescentes: Manual para a prática clínica (pp. 161-178, M. R. Hofmeister, Trad.). Porto Alegre, RS: Artes Médicas. (Original publicado em 1996)

Jonzon, E., \& Lindblad, F. (2004). Disclosure, reactions and social support: Findings from a sample of adult victims of child sexual abuse. Child Maltreatment, 9(2), 190-200. 
Kaplan, H. I., \& Sadock, B. J. (1997). Compêndio de Psiquiatria: Ciências do comportamento e Psiquiatria Clínica (7. ed., D. Batista, Trad.). Porto Alegre, RS: Artes Médicas. (Original publicado em 1994).

Kellogg, N. D., \& Menard, S. W. (2003). Violence among family members of children and adolescents evaluated for sexual abuse. Child Abuse \& Neglect, 27, 1367-1376.

Kristensen, C. H., Oliveira, M. S., \& Flores, R. Z. (1999). Violência contra crianças e adolescentes na Grande Porto Alegre: Pode piorar? In Associação de Apoio à Criança e ao Adolescente (Ed.), Violência doméstica (pp. 104-117). São Leopoldo, RS: AMENCAR.

Morais, N. A., \& Koller, S. (2004). Abordagem ecológica do desenvolvimento humano, Psicologia positiva e resiliência: Ênfase na saúde. In S. Koller (Ed.), Ecologia do desenvolvimento humano: Pesquisa e intervenção no Brasil (pp. 91-107) São Paulo, SP: Casa do Psicólogo.

Osofsky, J. D. (1995). The effects of exposure to violence on young children. American Psychologist, 50(9), 782-788.
Runyon, M. K., \& Kenny, M. C. (2002). Relationship of attributional style, depression and posttrauma distress among children who suffered physical or sexual abuse. Child Maltreatment, 7(3), 254-264.

Saywitz, K. J., Mannarino, A. P., Berliner, L., \& Cohen, J. A. (2000). Treatment for sexually abused children and adolescents. American Psychologist, 55(9), 1040-1049.

Thomas, M., Eckenrode, J., \& Garbarino (1997). Family sexual abuse. In J. Garbarino \& J. Eckenrode (Eds.), Understanding abusive families: An ecological approach to theory and practice (pp.114-130). San Francisco: Jossey-Bass.

Zavaschi, M. L. S., Telelbom, M., Gazal, C. H., \& Shansis, F. M. (1991). Abuso sexual na infância: Um desafio terapêutico. Revista de Psiquiatria, RS, 13(3), 136-145.

Recebido: 16/05/2005

$1^{a}$ revisão: $10 / 10 / 2005$

Aceite final: 15/12/2005 